\title{
Utility of fetal facial markers on a second trimester genetic sonogram in screening for Down syndrome in a high-risk Thai population
}

\author{
Savitree Pranpanus ${ }^{*}$, Kanokkarn Keatkongkaew and Manaphat Suksai
}

\begin{abstract}
Background: To establish the reference ranges and evaluate the efficacy of the fetal facial sonomarkers prenasal thickness (PT), nasal bone length (NBL), PT/NBL ratio and NBL/PT ratio for Down syndrome screening in the second trimester of high-risk pregnancies using two-dimensional (2D) ultrasound.
\end{abstract}

Methods: A prospective study was done in Thai pregnant women at high risk for structural and chromosomal abnormalities between May 2018 and May 2019. The main exclusion criteria were any fetal anatomical anomaly detected on ultrasonography or postpartum examination, abnormal chromosome or syndrome other than Down syndrome. Ultrasounds were performed in 375 pregnant women at 14 to 22 weeks' gestation and the fetal facial parameters were analyzed. Down syndrome results were confirmed by karyotyping. The reference ranges of these facial ultrasound markers were constructed based on the data of our population. The Down syndrome screening performance using these facial ultrasound markers was evaluated.

Results: In total, 340 euploid fetuses and 11 fetuses with Down syndrome met the inclusion criteria. The PT, NBL, and PT/NBL ratios in the euploid fetuses gradually increased with gestation progression while the NBL/PT ratio gradually decreased between 14-22 weeks' gestation. The NBL, PT/NBL ratio, and NBL/PT ratio all had 100\% sensitivity and PT had $91 \%$ sensitivity. These facial markers had 100\% negative predictive value for Down syndrome screening in the second trimester. The Bland-Altman analysis showed the intra- and inter-observer variations of PT and NBL had high intraclass correlation coefficients (ICC) in both operators, with ICCs of 0.98 and 0.99 and inter-observer ICCs of 0.99 for both operators.

Conclusion: The facial ultrasound markers are very useful for second trimester Down syndrome screening in our population. These facial ultrasound markers were easily identifiable and highly consistent either intra- or inter-operator by using widely-available 2D ultrasound. However, the reference ranges for these markers need to be constructed based on individual populations.

Trial registration: Registration number: REC 61-029-12-3. Date of registration: 18 May 2018.

Keywords: Prenasal thickness, Nasal bone length, Prenasal thickness to nasal bone length ratio, Nasal bone to prenasal thickness ratio, Facial sonomarkers, Second trimester, Down syndrome screening

*Correspondence: savitree.p@psu.ac.th; savitree46@hotmail.com

Maternal and Fetal Medicine Unit, Department of Obstetrics

and Gynecology, Faculty of Medicine, Prince of Songkla University, Hat Yai,

Songkhla 90110, Thailand

(c) The Author(s) 2022. Open Access This article is licensed under a Creative Commons Attribution 4.0 International License, which permits use, sharing, adaptation, distribution and reproduction in any medium or format, as long as you give appropriate credit to the original author(s) and the source, provide a link to the Creative Commons licence, and indicate if changes were made. The images or other third party material in this article are included in the article's Creative Commons licence, unless indicated otherwise in a credit line to the material. If material is not included in the article's Creative Commons licence and your intended use is not permitted by statutory regulation or exceeds the permitted use, you will need to obtain permission directly from the copyright holder. To view a copy of this licence, visit http://creativecommons.org/licenses/by/4.0/. The Creative Commons Public Domain Dedication waiver (http://creativeco mmons.org/publicdomain/zero/1.0/) applies to the data made available in this article, unless otherwise stated in a credit line to the data. 


\section{Background}

Down syndrome, first described in 1866, is one of the most common fetal aneuploidies [1]. The typical Down syndrome profile includes a flat face with a flat nose and subcutaneous skin edema. Abnormalities of the lymphatic vessels result in variable degrees of skin edema and an increasing of skin thickness in particular areas such as the face and nuchal fold $[2,3]$.

These common collective findings can thus be used as a screening tool for fetuses with Down syndrome in the first [3-6] and second trimesters [7-11]. There have been reports of some facial ultrasound markers that may be useful in the second trimester for Down syndrome screening, for example the absence or hypoplasia of the nasal bone, prenasal thickness (PT), frontomaxillary facial angle and prefrontal space ratio (PFSR) [10, 12-19]. All of these facial ultrasound markers can be measured with one standard ultrasound midsagittal fetal facial view in the second trimester [20]. These measurements are not difficult to perform, and various studies have found the acquisition of these images and the resulting measurements to have good reproducibility $[11,16]$.

There is strong evidence that an absent or hypoplastic nasal bone is a potential marker for Down syndrome screening in the second trimester [9, 21, 22]. However, this marker has differences in the normal ranges among races and ethnicities $[8,11,12]$, and when using reference ranges from other countries the detection rate has been found to be lower than expected in Asians [23]. Recently, the PT to NBL (PT/NBL) ratio has been widely reported as the most effective sonomarker for Down syndrome screening $[7,10,11,24-26]$. These studies reported detection rates of $\mathrm{PT} / \mathrm{NBL}$ for Down syndrome of $86-100 \%$. However, there is only one study from Asia, which was done in Chinese women, which found a lower detection rate of $46 \%$ for PT/NBL for Down syndrome screening when using 3D ultrasound [15], although the mean PT/NBL ratio in euploid fetuses and cut-off for Down syndrome screening were different from previous studies $[7,12,15,24,25]$.

In this study, our objective was to establish the reference ranges and evaluate the screening performance of PT, NBL, PT/NBL ratio and NBL/PT ratio for Down syndrome screening in second trimester women in our Thai population. We also wanted to examine the possible extra benefits of facial ultrasound markers in identifying women at high risk for aneuploidy and/or structural abnormalities.

\section{Methods}

A prospective study was carried out in 375 singleton, high-risk-pregnancies who underwent ultrasound scans at 14-22 weeks' gestation between May 2018 and May
2019. The criteria for high-risk pregnancy were advanced maternal age ( $\geq 35$ years), presence of one or more soft ultrasound markers from a previous ultrasound, a previous history of aneuploidy or congenital abnormality fetuses and/or patients identified as high risk for having a Down syndrome fetus following a national quadruple screening test in Thailand. The study was approved by the Ethics Committee of the Faculty of Medicine, Prince of Songkla University, Thailand. All of the study women were provided information about the purposes and methods of the study and provided written informed consent before undergoing their ultrasounds.

The gestational age was calculated from a first or second trimester scan before 20 weeks gestation. Fetal karyotyping was performed if amniocentesis was indicated. In participants with no karyotyping, the neonatal outcomes were determined from post-delivery pediatrician reports. The exclusion criteria were non-singleton pregnancies, non-Thai ethnicity, any anatomical anomaly detected on ultrasonography or postpartum examination, abnormal chromosome or syndrome other than Down syndrome, miscarriage or fetal death before 24 weeks, and/or neonatal outcomes information not available.

\section{Measurements}

Each woman was scanned by 2-dimensional (2D) transabdominal ultrasound, with a GE Voluson S10 or Voluson E8 system equipped with a RAB4-8L probe (GE Medical Systems, Kretz Ultrasound, Zipf, Austria). The first 100 cases were done by two sonographers with different degrees of experience; one had experience of less than five years and the second one had experience of over 5 years. This was done with the intent to evaluate the agreement between the two sonographers. The rest of the participants were scanned by one of these two sonographers. Each sonographer took $10 \mathrm{~min}$ for scanning each participant and if the measurements could not be achieved in that time, that participant was excluded. Each pregnant woman was scanned only one time. The sonographers were unaware of the karyotype because all the participants underwent their ultrasound before amniocentesis. The measurements were performed according to the criteria described originally by Maymon et al. [12] The exact mid-sagittal plane was defined according to the standard landmarks of the forehead, tip of the nose, visible translucent diencephalon or corpus callosum and palate without a zygomatic bone. PT was measured at the shortest distance between the anterior edge of the lowest part of the frontal bone and the facial skin anteriorly, as shown in Fig. 1. NBL was measured from the junction of the nasal and frontal bones to the distal edge of the white ossification line. These two parameters were measured 3 times in each fetus and the average of the 3 


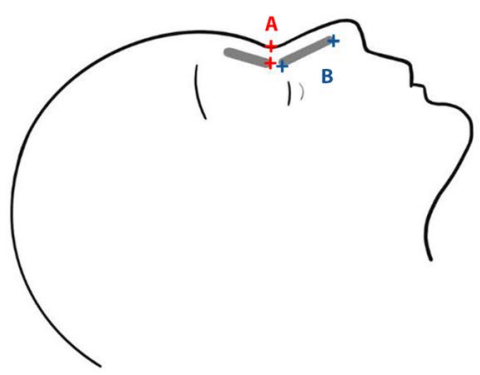

A
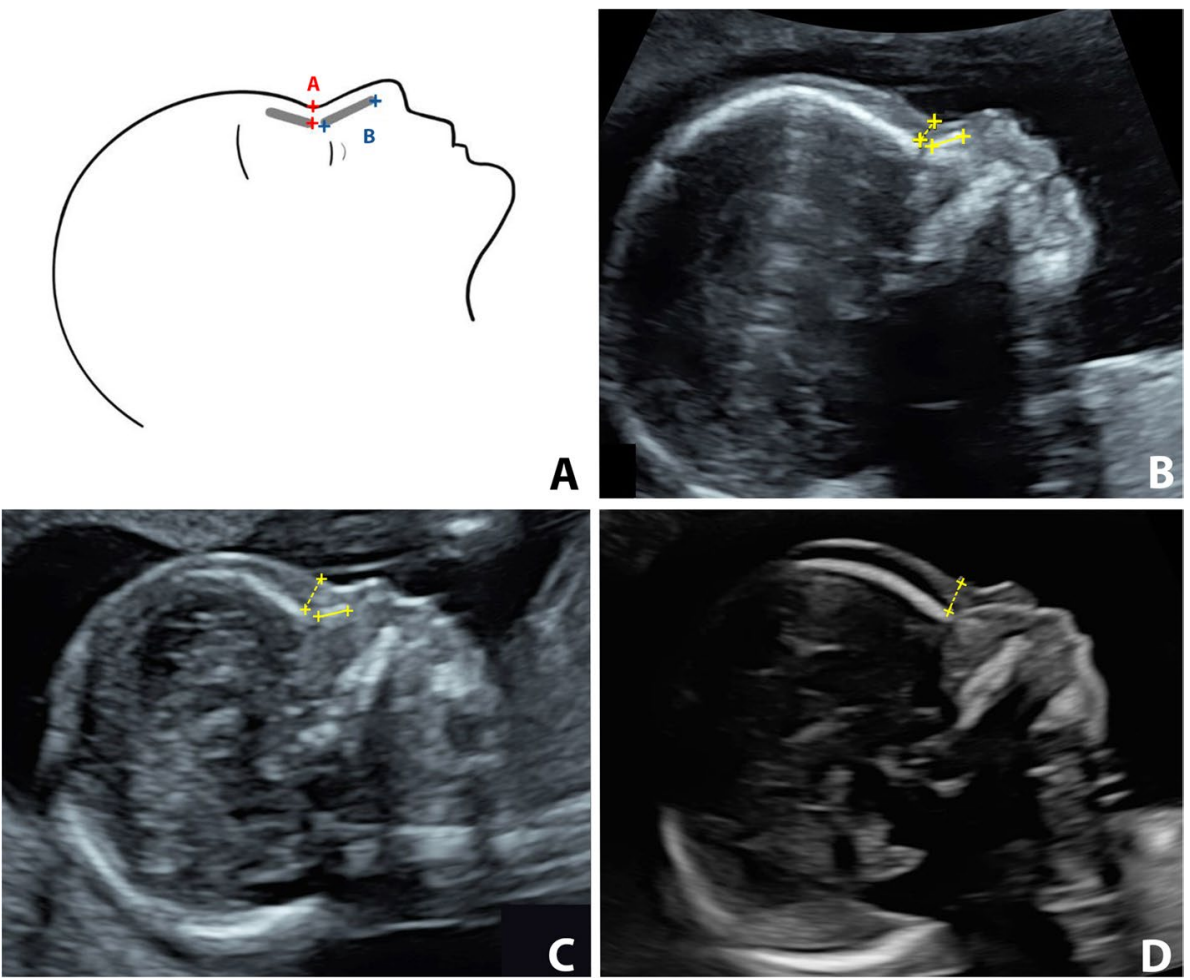

Fig. 1 Measurement of mid-facial plane facial ultrasound markers. Legend: The landmarks used for measurement of the facial ultrasound markers in the study are shown in (A). PT is the distance between the edge of the lowest part of the frontal bone and the facial skin anteriorly (A), NBL is measured at the ossification line along the fetal nose (B). Also shown are ultrasound images of the mid-facial plane in a euploid fetus (B) and a Down syndrome fetus with a hypoplastic nasal bone (C) and absent nasal bone (D). PT: prenasal thickness; NBL: nasal bone length.

measurements was used for the final analysis for Down syndrome screening.

\section{Statistical analysis}

Maternal demographic and ultrasonographic data and neonatal outcomes were recorded in Microsoft Excel. Statistical analyses were performed using Stata v14.2. Continuous variables were calculated as mean \pm SD. The distributions of PT and NBL (in $\mathrm{mm}$ ), and PT/NBL and $\mathrm{NBL} / \mathrm{PT}$ ratios according to gestational age were visualized using scatter plots. Using the euploid fetuses data, linear regression models for each marker (PT, NBL, PT/ $\mathrm{NBL}$ and $\ln [\mathrm{NBL} / \mathrm{PT}]$ ) were constructed against gestational age represented by days and days ${ }^{2}$ to predict mean values according to gestational age. Predicted percentiles $\left(5^{\text {th }}\right.$ and $\left.95^{\text {th }}\right)$ for each marker were constructed from mean marker level $\pm 1.64^{*}$, the standard deviation of the residuals obtained from the corresponding linear regression model. The percentile values of PT, NBL and $\mathrm{PT} / \mathrm{NBL}$ and exponentiated percentiles of $\ln (\mathrm{NBL} / \mathrm{PT})$ together with the original data of the euploid fetuses were plotted against gestational age. Marker levels from the fetuses with Down syndrome were added to the graphs to compare with the levels from the euploid fetuses. Using the $5^{\text {th }}$ and $95^{\text {th }}$ percentiles according to the marker concerned, the predictive properties of each marker were estimated.

The agreements between the two measurements of each observer were evaluated from the first 100 cases during the study period. The PT and NBL were evaluated, and intraobserver and interobserver agreements calculated using Bland-Altman analysis and intraclass correlation coefficient (ICC). In all analyses, $\mathrm{P}<0.05$ was considered to be statistically significant.

\section{Results}

A total of 375 pregnant women who underwent ultrasound in our high-risk clinic were enrolled in this study. A sagittal view of the fetal face was obtained within 10 min from a $2 \mathrm{D}$ ultrasound in $99.7 \%$ of the participants. Twenty-four women were excluded from the study. Four of the 24 had fetal structural abnormalities detected during their ultrasounds, 2 cystic hygromas, 1 congenital heart defect, 1 severe ventriculomegaly. Six cases had fetal chromosomal abnormalities other than Down syndrome, 3 Trisomy 18, 1 each of 45, X, 47,XXX 
Table 1 Characteristics of the study population

\begin{tabular}{|c|c|c|c|}
\hline Parameter & $\begin{array}{l}\text { Euploid fetuses } \\
(n=340)\end{array}$ & Fetuses with Down syndrome $(n=11)$ & $P$ value \\
\hline $\begin{array}{l}\text { Maternal age } \\
\text { (median, years) }\end{array}$ & $35(32,37.25)$ & $39(34.5,39.5)$ & 0.0788 \\
\hline $\begin{array}{l}\text { Gestational age at ultrasound } \\
\text { (median, weeks) }\end{array}$ & $17(16,20)$ & $18(18,20)$ & 0.0887 \\
\hline $\begin{array}{l}\text { PT }(\mathrm{mm}) \\
\text { median }(\min , \max )\end{array}$ & $2.73(2.33,3.3)$ & $4.8(4.1,5.2)$ & $<0.001$ \\
\hline $\begin{array}{l}\mathrm{NBL}(\mathrm{mm}) \\
\text { median (min,max) }\end{array}$ & $5.4(5,6.1)$ & $1.4(1.07,1.8)$ & $<0.001$ \\
\hline $\begin{array}{l}\text { PT/NBL ratio } \\
\text { median (min,max) }\end{array}$ & $0.5(0.46,0.55)$ & $3(2.65,4.7)$ & $<0.001$ \\
\hline $\begin{array}{l}\text { NBL/PT ratio } \\
\text { median (min,max) }\end{array}$ & $2(1.81,2.18)$ & $0.33(0.2,0.38)$ & $<0.001$ \\
\hline
\end{tabular}

Min Minimum, Max Maximum, PT Prenasal thickness, NBL Nasal bone length

and 47,XXY, and 14 were lost to follow up, leaving 351 women included in the final analysis. The characteristics of the study population are presented in Table 1. The median age of the participants was 35 years (range $15-45$ years) and $59.1 \%$ were $\geq 35$ years. All participants were of Thai ethnicity. A majority of the participants were gravidas of advanced maternal age who had amniocentesis (61.5\%). Karyotyping was performed in women who underwent amniocentesis and newborn outcomes were determined after delivery. The median gestational age at birth of the euploid fetuses was 38 weeks 6 days with a median birth weight of 3,012 g. Ten of the 11 Down syndrome pregnancies were terminated before 24 weeks gestation.

All facial ultrasound markers of the fetuses with Down syndrome were statistically significantly different from the euploid fetuses as shown in Table 1. All fetuses with Down syndrome had abnormal PT/NBL and NBL/PT ratios. Hypoplastic NBL was found in 10/11 cases, while only 1 case had an absent nasal bone, in a mother who was 17 years old. Five of the 11 Down mothers had amniocentesis because of maternal age and only 1 of these 5 fetuses had a soft ultrasound marker, which was bilateral mild pyelectasis. Three cases underwent amniocentesis due to being found to be at high risk for a Down syndrome fetus from a quad test. Two cases underwent amniocentesis because of hypoplastic nasal bones and other soft ultrasound markers found during routine fetal anatomical scans. The last case had a fetus with mild pyelectasis and mild ventriculomegaly.

The mean PT, NBL, and PT/NBL and NBL/PT ratios of the euploid fetuses weekly from 14 to 22 weeks gestation are shown in Table 2. The mean PTs, NBLs, and PT/ NBL ratios of our participants gradually increased while the NBL/PT ratios gradually decreased with advancing
Table 2 The mean facial ultrasound markers of the euploid fetuses in our study during the second trimester

\begin{tabular}{lllll}
\hline GA (Weeks) & PT $(\mathbf{m m})$ & NBL $(\mathbf{m m})$ & PT/NBL & NBL/PT \\
\hline 14 & 1.83 & 3.86 & 0.48 & 2.27 \\
15 & 2.17 & 4.57 & 0.47 & 2.21 \\
16 & 2.47 & 4.97 & 0.5 & 2.11 \\
17 & 2.71 & 5.36 & 0.51 & 2.06 \\
18 & 2.88 & 5.91 & 0.49 & 2.14 \\
19 & 3.22 & 6.06 & 0.53 & 1.93 \\
20 & 3.49 & 6.15 & 0.57 & 1.82 \\
21 & 3.6 & 6.38 & 0.56 & 1.83 \\
22 & 3.75 & 6.5 & 0.58 & 1.78 \\
\hline
\end{tabular}

GA Gestational age (weeks), PT Prenasal thickness, NBL Nasal bone length

gestational age. Regression analysis was performed to predict the $5^{\text {th }}$ and $95^{\text {th }}$ percentiles of each facial parameter as shown in Table 3. All fetuses with Down syndrome had PTs, NBLs and NBL/PT ratios less than the $5^{\text {th }}$ percentile of euploid fetuses at the same gestational ages, while the $\mathrm{PT} / \mathrm{NBL}$ ratio was higher than the $95^{\text {th }}$ percentile in all fetuses with Down syndrome (Fig. 2).

The screening performance of the facial ultrasound markers is shown in Table 4. When using the predicted cut offs of NBL and NBL/PT ratio lower than the $5^{\text {th }}$ and $\mathrm{PT}$ and PT/NBL ratio higher than the $95^{\text {th }}$ percentiles of each gestational age, the NBL and PT/NBL and NBL/PT ratios showed sensitivity of $100 \%$ and specificity of $92 \%$. When using a PT cut-Foff higher than the $95^{\text {th }}$ percentile, the sensitivity was lower than the other parameters at $91 \%$ but had a slightly higher specificity of $93 \%$. When comparing the appropriate levels based on our study for percentiles $\left(5^{\text {th }}\right.$ and $\left.95^{\text {th }}\right)$ for each marker as estimated from the predicted mean markers that gave $100 \%$ sensitivity, the PT/NBL ratio had the lowest false positive rate 
Table 3 The predictive properties of the $5^{\text {th }}$ and $95^{\text {th }}$ percentiles of each facial ultrasound marker

\begin{tabular}{|c|c|c|c|c|c|c|c|c|}
\hline \multirow{2}{*}{$\begin{array}{l}\text { GA } \\
\text { (weeks) }\end{array}$} & \multicolumn{2}{|c|}{ PT (mm) } & \multicolumn{2}{|c|}{ NBL (mm) } & \multicolumn{2}{|c|}{ PT/NBL Ratio } & \multicolumn{2}{|c|}{ NBL/PT Ratio } \\
\hline & $5^{\text {th }}$ & $95^{\text {th }}$ & $5^{\text {th }}$ & $95^{\text {th }}$ & $5^{\text {th }}$ & $95^{\text {th }}$ & $5^{\text {th }}$ & $95^{\text {th }}$ \\
\hline 14 & 1.06 & 2.47 & 3.18 & 4.74 & 0.34 & 0.56 & 1.80 & 2.80 \\
\hline 15 & 1.40 & 2.81 & 3.75 & 5.31 & 0.36 & 0.57 & 1.74 & 2.71 \\
\hline 16 & 1.71 & 3.11 & 4.25 & 5.81 & 0.37 & 0.59 & 1.69 & 2.63 \\
\hline 17 & 1.99 & 3.40 & 4.67 & 6.23 & 0.39 & 0.60 & 1.66 & 2.55 \\
\hline 18 & 2.24 & 3.65 & 5.02 & 6.58 & 0.40 & 0.62 & 1.59 & 2.47 \\
\hline 19 & 2.47 & 3.88 & 5.29 & 6.85 & 0.42 & 0.63 & 1.54 & 2.40 \\
\hline 20 & 2.66 & 4.07 & 5.48 & 7.04 & 0.43 & 0.65 & 1.50 & 2.33 \\
\hline 21 & 2.83 & 4.24 & 5.61 & 7.16 & 0.45 & 0.66 & 1.46 & 2.27 \\
\hline 22 & 2.97 & 4.38 & 5.65 & 7.21 & 0.46 & 0.68 & 1.42 & 2.21 \\
\hline
\end{tabular}

GA Gestational age (weeks), PT Prenasal thickness, NBL Nasal bone length

of $6.5 \%$, which gave an area under the curve (AUC) of 0.97 . We had $0 \%$ false negatives when using the NBL cut off or NBL/PT ratio lower than the $5^{\text {th }}$ percentile or $\mathrm{PT} /$ NBL ratio higher than the $95^{\text {th }}$ percentile.

The Bland-Altman method was used to assess the intra- and inter-observer variability in measurements of the facial ultrasound markers of the operators in the study as shown in Table 5. Both the intra- and interobserver variations of PT and NBL had high intraclass correlation coefficients (ICC) in both operators, with ICCs of 0.98 and 0.99 and inter-observer ICCs of 0.99 for both operators. The mean differences of PT and NBL were $0.01 \mathrm{~mm}(\mathrm{SD}=0.08)$ and $-0.01 \mathrm{~mm}(\mathrm{SD}=0.11)$, respectively.

\section{Discussion}

Our study found as in other studies that a facial profile view of a fetus using a $2 \mathrm{D}$ ultrasound scan during the second trimester was not difficult to perform and could be done with a high level of reproducibility $[11,16]$ and high inter- and intra-observer agreements. A previous study reported that measuring facial ultrasound markers with 2D ultrasound as a screening protocol in the clinic had a comparable efficacy with 3D ultrasound [25]. However the use of 3D ultrasound can be limited in a difficult circumstance such as a low level of amniotic fluid [27], and if acquisition of a midsagittal facial plane image is not accomplished, the NBL measurement may be overestimated [28].

Our study found as in other studies that both PT and NBL in euploid fetuses increased with gestational age in the second trimester [11, 12, 15, 25, 29]. However, the predicted means and $5^{\text {th }}$ and $95^{\text {th }}$ percentiles of NB and PT in our euploid fetuses were found to be different during the second trimester among studies in Caucasian and Chinese participants $[7,11,15,30]$.
The mean PT in our study was slightly shorter than in other studies conducted in Caucasian and Chinese women $[11,12,15,24]$. The mean NBL in the second trimester fetuses of our population was similar to the previously mentioned Chinese study [15], but slightly shorter than in euploid Caucasian fetuses [7, 12, 29]. The PT/ NBL ratio of our euploid fetuses gradually increased during the second trimester, in contrast with other Caucasian and Chinese studies which showed a constant ratio during the second trimester $[7,15,25,30]$, while some of the Caucasian studies showed a gradual decrease during the second to early third trimesters $[11,12,29]$. This result of our study could be explained from the minimally shorter NBL of our euploid fetuses compared with Caucasian and Chinese fetuses at the same gestational age. The NBL/PT ratio in the euploid fetuses of our study gradually decreased during the second trimester, while one of the studies in Caucasians reported a gradual increase in this ratio during the second trimester [11]. The results of our study could be explained from the increase of PT in advancing gestational age while the NBL only minimally increased with advancing gestational age of our euploid fetuses.

Our study confirms that PT is significantly thicker and NBL significantly shorter in fetuses with Down syndrome in the second trimester. The PT/NBL ratio was higher and the NBL/PT ratio was lower in fetuses with Down syndrome in our study, similar to the findings from other studies in both Caucasian and Chinese fetuses $[12,15,24,25]$. For the cut off of the PT/NBL ratio for Down syndrome screening, most previous studies used a cut-off at more than the $95^{\text {th }}$ percentile of the gestation, as in our study $[7,15]$. However, some studies have suggested using a stable cut-off at the $95^{\text {th }}$ percentile of PT/NBL ratios because they found a stable PT/NBL ratio throughout the gestational periods 

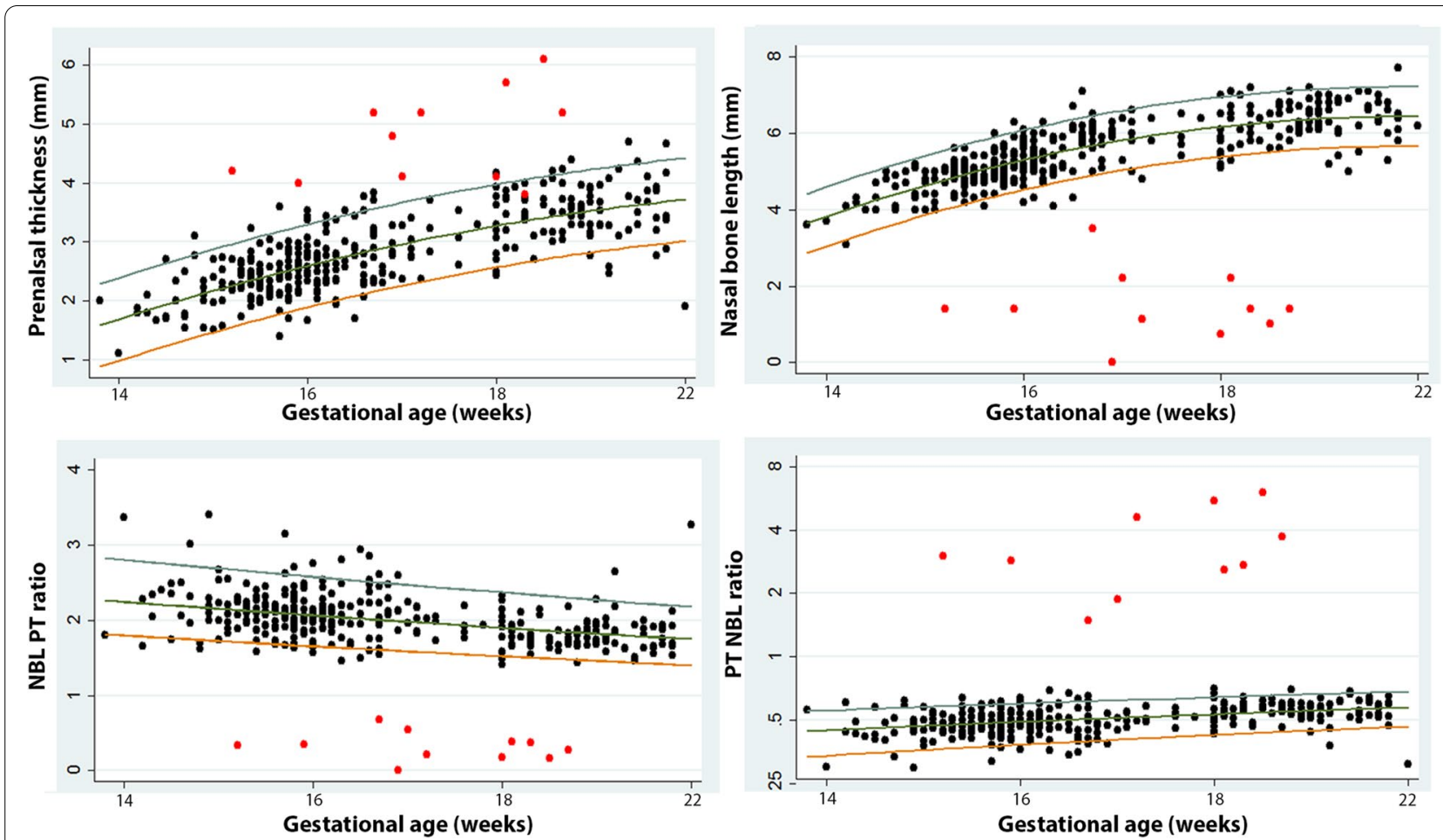

Fig. 2 The distribution of facial ultrasound markers in the study euploid fetuses and fetuses with Down syndrome. Legend: PT, NBL, and PT/NBL and NBL/PT ratios according to gestational age of 340 euploid fetuses (black circles) and 11 fetuses with Down syndrome (red circles). PT prenasal thickness; NBL nasal bone length.

Table 4 Screening performance of the studied facial ultrasound markers for the fetuses with Down syndrome

\begin{tabular}{lllll}
\hline & PT & NBL & PT/NBL ratio & NBL/ PT ratio \\
\hline Sensitivity (\%) & 91 & 100 & 100 & 100 \\
Specificity (\%) & 93 & 92 & 92 & 92 \\
False positive (\%) & 6.76 & 7.6 & 6.5 & 7.6 \\
False negative (\%) & 9.0 & 0 & 0 & 0 \\
Positive predictive value & 30 & 30 & 30 & 30 \\
Negative predictive value & 100 & 100 & 100 & 100 \\
Positive likelihood ratio & 13.44 & 13.08 & 13.08 & 13.08 \\
Negative likelihood ratio & 0.14 & 0.00 & 0.00 & 0.00 \\
AUC & 0.921 & 0.962 & 0.968 & 0.969 \\
\hline
\end{tabular}

AUC Area under the curve, PT Prenasal thickness, NBL Nasal bone length

$[24,25]$. Ours is the first study in an Asian population to examine the NBL/PT ratio, and we found different values from a Caucasian study [11]. Our study found a small but significant decrease in the NBL/PT ratio in advancing gestation. Thus, we support using an NBL/ $\mathrm{PT}$ ratio less than the 5 th percentile of the gestation as a cut off for Down syndrome screening in our population. Our findings also indicate that the cut off values for facial ultrasound markers used for Down syndrome screening in the second trimester need to be constructed based on ethnicity.

Our study found that Down syndrome screening using these facial ultrasound markers in Asian fetuses was highly effective, as also found in previous studies in Caucasians, a high detection rate using the PT/NBL ratio was also found in a study of De Jong-Pleij et al. done in a highrisk pregnancy group [25]. However, we found a slightly higher false positive rate of $6.5 \%$ compared to De JongPleij's $5 \%$. The previously mentioned study in Chinese patients found a low detection rate of the PT/NBL ratio of $46 \%$ and a $5 \%$ false positive rate, but when using the stable cut-off of 0.8 as in Caucasians the detection rate was $80.9 \%$ although with a substantially increased false positive rate of $21.6 \%$ [15]. These findings support the hypothesis that screening programs for Asian fetuses cannot use the Caucasian cut offs for facial ultrasound markers. Our study is the first to report on the performance of the NBL/ PT ratio in an Asian population for Down screening and we found a high detection rate of $100 \%$ with a false positive rate of $7.6 \%$ and false negative rate of $0 \%$, compared with the study of Szabo in Caucasians using this ratio which found a detection rate of $96.9 \%$ but with a lower false positive rate of $1.7 \%$ and false negative rate of $30.3 \%$ [11]. In assessing the screening performance of our study, 
Table 5 Intraobserver and interobserver variability for the PT and NBL measurements

\begin{tabular}{|c|c|c|c|c|c|c|c|c|}
\hline \multicolumn{9}{|c|}{ Intraobserver variability $(n=100)$} \\
\hline \multirow[t]{2}{*}{ Parameter } & \multicolumn{4}{|c|}{ Operator 1} & Operator 2 & & & \\
\hline & $\begin{array}{l}\text { Mean differ- } \\
\text { ence (SD) }\end{array}$ & $95 \%$ LoA & & ICC & $\begin{array}{l}\text { Mean differ- } \\
\text { ence (SD) }\end{array}$ & \multicolumn{2}{|l|}{$95 \%$ LoA } & ICC \\
\hline PT & $-0.04(0.11)$ & -0.06 to -0.01 & & 0.98 & $-0.02(0.12)$ & -0.04 to 0.003 & & 0.99 \\
\hline NBL & $0.05(0.16)$ & 0.02 to 0.08 & & 0.98 & $-0.03(0.15)$ & -0.06 to -0.001 & & 0.98 \\
\hline \multicolumn{9}{|c|}{ Interobserver variability $(n=100)$} \\
\hline & \multicolumn{2}{|c|}{ Mean difference (SD) } & \multicolumn{2}{|l|}{$95 \%$ LoA } & & \multicolumn{3}{|c|}{ ICC } \\
\hline PT & \multicolumn{2}{|l|}{$0.01(0.08)$} & \multicolumn{2}{|l|}{-0.003 to 0.03} & & \multicolumn{3}{|c|}{0.99} \\
\hline NBL & \multicolumn{2}{|l|}{$-0.01(0.11)$} & \multicolumn{2}{|l|}{-.022 to 0.02} & & \multicolumn{3}{|c|}{0.99} \\
\hline
\end{tabular}

SD Standard deviation, LOA Limits of agreement, ICC intraclass correlation, PT Prenasal thickness, NBL Nasal bone length

the NBL and PT/NBL and NBL/PT ratios had $0 \%$ negative predictive value with AUCs of 0.96, 0.97 and 0.97, respectively. We conclude that the use of facial ultrasound markers should be encouraged to increase the detection rate of Down syndrome screening in the second trimester in our population.

With current advances in prenatal screening for Down syndrome, cell-free DNA has become the most effective Down screening method [31]. However, this screening method is costly, and limited to only some centers in lowresource or developing countries [32]. There is evidence showing that using multiple soft ultrasound markers can increase the detection rate of Down syndrome [9]. However, using multiple soft ultrasound markers for Down syndrome screening is not universal because of a lack of expertise in many centers and the longer time required. A related study found that adding genetic sonogram screening in pregnancies identified as low risk for a Down syndrome fetus by cell-free DNA had a low positive predictive value [33]. To optimize the screening performance for Down syndrome, particularly in some developing countries in which maternal serum biomarkers are currently used but have lower detection rates than expected, such as in our setting [34], our study supports the idea of adding facial ultrasound markers in groups at moderate risk for Down syndrome to maternal serum biomarkers. As a previous study using only absent or hypoplastic nasal bone for Down syndrome screening reported a low detection rate for Down syndrome in Asian fetuses [35], adding multiple facial ultrasound markers should increase the detection rate of Down syndrome screening in our populations [36]. As another potential benefit of using facial ultrasound markers screening, a recent study found that the presence of isolated facial ultrasound markers such as a hypoplastic nasal bone could indicate other fetal chromosomal abnormalities and pathogenic copy number variants [37]. In such cases, if abnormal facial ultrasound markers are found, then an increased risk of Down syndrome would indicate the patient should be considered for amniocentesis.

Our study was done in a homogeneous group of Thai women. This is the first study done in an Asian group to assess the appropriate reference ranges of potential facial ultrasound markers, and we found high performance in screening for Down syndrome in the second trimester. Our suggested reference ranges can be combined with the other screening methods that are offered in the first or second trimester as an adjunct test to increase the detection rate of Down syndrome screening or at places that lack fetal medicine specialists to perform genetic sonograms as a universal screening program. From the variety of measurement techniques available, in our study we chose 2D ultrasound, which is widely used, practical for general obstetricians, and takes less time to learn compared with the 3D technique. Also, these facial parameters had high inter-observer agreement for the measurements. All of these facts support our suggestion that fetal facial ultrasound markers should be promoted as a routine or adjunct to a screening program by general obstetricians in our population.

Our study had some limitations. First, the number of fetuses with Down syndrome was smaller than in other studies. Also, our study was done only in a high-risk population, thus the results may not reflect the actual proportions in a mixed-risk population. We also had a limited number of cases in some gestational age periods, and thus our findings may not reflect the normal distribution of facial parameters in euploid fetuses.

\section{Conclusion}

To measure fetal facial ultrasound markers with 2D ultrasound in the second trimester is not difficult, has highly consistent results among operators and had a high performance for Down syndrome screening in our population. However, the reference ranges of facial ultrasound markers need to be constructed based on ethnicities. 


\section{Abbreviations}

PT: Prenasal thickness; NBL: Nasal bone length; PT/NBL ratio: Prenasal thickness to nasal bone length ratio; nasal bone length to prenasal thickness ratio; 2D ultrasound: 2-Dimensional ultrasound; ICC: Intraclass correlation coefficient; min: Minimum; max: Maximum.

\section{Acknowledgements}

The authors would like to thank all supporting nurses and staff of the Maternal Fetal Medicine Unit, Faculty of Medicine, Prince of Songkla University for their contributions to collecting data, and Dr. Alan Geater, Ms. Walailuk Jitpiboon and Ms. Nannapat Pruphetkaew of the Epidemiology Unit for their help with statistical analysis and consultations.

\section{Authors' contributions}

SP: Conceptualization, study design, proposal writing, investigation, acquisition of data, data analysis, manuscript writing. KK: investigation, acquisition of data. MS: investigation. All author(s) read and approved the final manuscript.

\section{Funding}

Funding for the study was provided by the Research Fund, Faculty of Medicine, Prince of Songkla University; the funder had no role in the design of the study and collection, analysis, and interpretation of data or in writing the manuscript.

\section{Availability of data and materials}

The datasets analyzed during the study are available from the corresponding author upon reasonable request.

\section{Declarations}

\section{Ethics approval and consent to participate}

This study was approved by the Institutional Review Board, Office of the Human Research Ethics Committee (HREC), Faculty of Medicine, Prince of Songkla University.

Approval Number: REC.61-029-12-3.

All of the patients who participated in this study were informed of the study design and aims and gave their written informed consent.

All methods were carried out in accordance with relevant guidelines and regulations.

\section{Consent for publication}

Not applicable.

\section{Competing interests}

The authors declare that they have no competing interests.

Received: 25 July 2021 Accepted: 3 December 2021

Published online: 11 January 2022

\section{References}

1. Down JL. Observations on an ethnic classification of idiots. 1866. Ment Retard. 1995:33:54-6.

2. von Kaisenberg CS, Krenn V, Ludwig M, Nicolaides KH, Brand-Saberi B. Morphological classification of nuchal skin in human fetuses with trisomy 21, 18, and 13 at 12-18 weeks and in a trisomy 16 mouse. Anat Embryol (Berl). 1998;197:105-24.

3. Bellini C, Rutigliani M, Boccardo FM, Bonioli E, Campisi C, Grillo F, Bellini T, Valenzano M, Fulcheri E. Nuchal translucency and lymphatic system maldevelopment. J Perinat Med. 2009;37:673-6.

4. Manegold-Brauer G, Bourdil L, Berg C, Schoetzau A, Gembruch U, Geipel A. Prenasal thickness to nasal bone length ratio in normal and trisomy 21 fetuses at 11-14 weeks of gestation. Prenat Diagn. 2015;35:1079-84.

5. Rao R, Platt LD. Ultrasound screening: Status of markers and efficacy of screening for structural abnormalities. Semin Perinatol. 2016;40:67-78.

6. Bakker M, Pace M, de Jong-Pleij E, Birnie E, Kagan KO, Bilardo CM. Prenasal Thickness, Prefrontal Space Ratio and Other Facial Profile Markers in
First-Trimester Fetuses with Aneuploidies, Cleft Palate, and Micrognathia. Fetal Diagn Ther. 2018;43:231-40.

7. Tournemire A, Groussolles M, Ehlinger V, Lusque A, Morin M, Benevent $J B$, Arnaud C, Vayssiere C. Prenasal thickness to nasal bone length ratio: effectiveness as a second or third trimester marker for Down syndrome. Eur J Obstet Gynecol Reprod Biol. 2015;191:28-32.

8. De Jong-Pleij EA, Ribbert LS, Tromp E, Bilardo CM. Three-dimensional multiplanar ultrasound is a valuable tool in the study of the fetal profile in the second trimester of pregnancy. Ultrasound Obstet Gynecol. 2010;35:195-200

9. Agathokleous M, Chaveeva P, Poon LC, Kosinski P, Nicolaides KH. Metaanalysis of second-trimester markers for trisomy 21. Ultrasound Obstet Gynecol. 2013;41:247-61.

10. Vos Fl, de Jong-Pleij EA, Bakker M, Tromp E, Kagan KO, Bilardo CM. Fetal facial profile markers of Down syndrome in the second and third trimesters of pregnancy. Ultrasound Obstet Gynecol. 2015:46:168-73.

11. Szabo A, Szili K, Szabo JT, Sikovanyecz J, Isaszegi D, Horvath E, Szabo J. Nasal bone length: prenasal thickness ratio: a strong 2D ultrasound marker for Down syndrome. Prenat Diagn. 2014;34:1139-45.

12. Maymon $R$, Levinsohn-Tavor $O$, Cuckle H, Tovbin $Y$, Dreazen $E$, Wiener $Y$, Herman A. Second trimester ultrasound prenasal thickness combined with nasal bone length: a new method of Down syndrome screening. Prenat Diagn. 2005;25:906-11.

13. Sonek JD, Nicolaides KH. Prenatal ultrasonographic diagnosis of nasal bone abnormalities in three fetuses with Down syndrome. Am J Obstet Gynecol. 2002;186:139-41.

14. Cicero S, Sonek JD, McKenna DS, Croom CS, Johnson L, Nicolaides KH. Nasal bone hypoplasia in trisomy 21 at 15-22 weeks' gestation. Ultrasound Obstet Gynecol. 2003;21:15-8.

15. Yang $X$, Zhen L, Pan M, Han J, Li D, Liao C. PT/NBL ratio assessment at mid-trimester in prenatal screening for Down syndrome in a Chinese population. J Matern Fetal Neonatal Med. 2014;27:1860-3.

16. Persico N, Borenstein M, Molina F, Azumendi G, Nicolaides KH. Prenasal thickness in trisomy-21 fetuses at 16-24 weeks of gestation. Ultrasound Obstet Gynecol. 2008;32:751-4.

17. Sonek J, Borenstein M, Downing C, McKenna D, Neiger R, Croom $\mathrm{C}$, Genrich T, Nicolaides KH. Frontomaxillary facial angles in screening for trisomy 21 at 14-23 weeks' gestation. Am J Obstet Gynecol. 2007;197(160):e161-165.

18. Molina F, Persico N, Borenstein M, Sonek J, Nicolaides KH. Frontomaxillary facial angle in trisomy 21 fetuses at 16-24 weeks of gestation. Ultrasound Obstet Gynecol. 2008:31:384-7.

19. Sonek J, Molina F, Hiett AK, Glover M, McKenna D, Nicolaides KH. Prefrontal space ratio: comparison between trisomy 21 and euploid fetuses in the second trimester. Ultrasound Obstet Gynecol. 2012;40:293-6.

20. Maymon R, Ushakov F, Waisman D, Cuckle H, Tovbin Y, Herman A. A model for second-trimester Down syndrome sonographic screening based on facial landmarks and digit length measurement. Ultrasound Obstet Gynecol. 2006;27:290-5.

21. Moreno-Cid M, Rubio-Lorente A, Rodriguez MJ, Bueno-Pacheco G, Tenias JM, Roman-Ortiz C, Arias A. Systematic review and meta-analysis of performance of second-trimester nasal bone assessment in detection of fetuses with Down syndrome. Ultrasound Obstet Gynecol. 2014;43:247-53.

22. Sonek J, Croom C. Second trimester ultrasound markers of fetal aneuploidy. Clin Obstet Gynecol. 2014;57:159-81.

23. Jung E, Won HS, Lee PR, Kim A. Ultrasonographic measurement of fetal nasal bone length in the second trimester in Korean population. Prenat Diagn. 2007;27:154-7

24. Ozcan T, Ozlu T, Allen J, Peterson J, Pressman EK. Predictive role of prenasal thickness and nasal bone for Down syndrome in the second trimester. Eur J Obstet Gynecol Reprod Biol. 2013:171:220-4.

25. De Jong-Pleij EA, Vos FI, Ribbert LS, Pistorius LR, Tromp E, Bilardo CM. Prenasal thickness-to-nasal bone length ratio: a strong and simple secondand third-trimester marker for trisomy 21. Ultrasound Obstet Gynecol. 2012;39:185-90.

26. Vos Fl, De Jong-Pleij EA, Bakker M, Tromp E, Pajkrt E, Kagan KO, Bilardo CM. Nasal bone length, prenasal thickness, prenasal thickness-to-nasal bone length ratio and prefrontal space ratio in second- and third-trimester fetuses with Down syndrome. Ultrasound Obstet Gynecol. 2015:45:211-6. 
27. Vos FI, Bakker M, de Jong-Pleij EA, Ribbert LS, Tromp E, Bilardo CM. Is 3D technique superior to 2D in Down syndrome screening? Evaluation of six second and third trimester fetal profile markers. Prenat Diagn. 2015;35:207-13.

28. Persico N, Molina F, Azumendi G, Fedele L, Nicolaides KH. Nasal bone assessment in fetuses with trisomy 21 at 16-24 weeks of gestation by three-dimensional ultrasound. Prenat Diagn. 2012;32:240-4.

29. Ozdemir H, Kalayci H, Yetkinel S, CokT, Coban G, Tarim E. The nomogram of prenasal thickness and nasal bone ratio and its relationship with nuchal fold in second-trimester fetal ultrasound. J Obstet Gynaecol Res. 2018;44:1063-71.

30. Altunkeser A, Korez MK. Reference ranges for foetal nasal bone length, prenasal thickness, and interocular distance at 18 to 24 weeks' gestation in low-risk pregnancies. BMC Pregnancy Childbirth. 2017;17:416.

31. Gil MM, Accurti V, Santacruz B, Plana MN, Nicolaides KH. Analysis of cell-free DNA in maternal blood in screening for aneuploidies: updated meta-analysis. Ultrasound Obstet Gynecol. 2017;50:302-14.

32. Garcia-Perez L, Linertova R, Alvarez-de-la-Rosa M, Bayon JC, Imaz-Iglesia I, Ferrer-Rodriguez J, Serrano-Aguilar P. Cost-effectiveness of cell-free DNA in maternal blood testing for prenatal detection of trisomy 21, 18 and 13: a systematic review. Eur J Health Econ. 2018;19:979-91.

33. Salomon LJ, Alfirevic Z, Audibert F, Kagan KO, Paladini D, Yeo G, RaineFenning N. ISUOG consensus statement on the impact of non-invasive prenatal testing (NIPT) on prenatal ultrasound practice. Z Geburtshilfe Neonatol. 2014;218:242-3.

34. Pranpanus S, Kor-Anantakul O, Suntharasaj T, Suwanrath C, Hanprasertpong T, Pruksanusak N, Petpichetchian C, Suksai M, Chainarong N, Sawaddisan R. Ethnic-specific reference range affects the efficacy of quadruple test as a universal screening for Down syndrome in a developing country. PLOS ONE. 2021;16:e0251381.

35. Hu T, Tian T, Zhang Z, Wang J, Hu R, Xiao L, Zhu H, Lai Y, Wang H, Liu S. Prenatal chromosomal microarray analysis in 2466 fetuses with ultrasonographic soft markers: a prospective cohort study. Am J Obstet Gynecol. 2020;224(5):516.e1-516.e16

36. Miguelez J, Moskovitch M, Cuckle H, Zugaib M, Bunduki V, Maymon R. Model-predicted performance of second-trimester Down syndrome screening with sonographic prenasal thickness. J Ultrasound Med. 2010;29:1741-7.

37. Lostchuck E, Hui L. Should second-trimester hypoplastic nasal bone be sole indication for diagnostic testing with chromosomal microarray analysis? Ultrasound Obstet Gynecol. 2019;53:848-50.

\section{Publisher's Note}

Springer Nature remains neutral with regard to jurisdictional claims in published maps and institutional affiliations.

Ready to submit your research? Choose BMC and benefit from:

- fast, convenient online submission

- thorough peer review by experienced researchers in your field

- rapid publication on acceptance

- support for research data, including large and complex data types

- gold Open Access which fosters wider collaboration and increased citations

- maximum visibility for your research: over $100 \mathrm{M}$ website views per year

At BMC, research is always in progress.

Learn more biomedcentral.com/submissions 